\title{
Epidemiological and Histopathological Profile of Gastric Adenocarcinoma at Brazzaville University Hospital
}

\author{
Fidele Mambouene', Anicet Boumba ${ }^{2}$, Fabien Mouamba ${ }^{3}$, Valere Belle mbou ${ }^{4}$, \\ Dimitry Moudiongui ${ }^{5}$, Deby Gassaye ${ }^{6}$, Jean Felix Peko ${ }^{7}$
}

\author{
${ }^{1}$ PhD Student Pending Defense in Service at the Pathological Anatomy Laboratory of the University Hospital of \\ Brazzaville \\ ${ }^{2}$ Oncology, Virology and Molecular Biology, General Hospital of Loandjili Pointe Noire \\ ${ }^{3}$ Pathologist and Assistant at the Faculty of Medicine, Pathological Anatomy Laboratory of the University \\ Hospital of Brazzaville \\ ${ }^{4}$ Pathologist and Hospital Practitioner, Poitier Hospital France, \\ ${ }^{5} \mathrm{PhD}$ Student Pending Defense in Service at the Pathological Anatomy Laboratory of the University Hospital of \\ Brazzaville \\ ${ }^{6}$ Hepato Gastroenterologist in the Gastroenterology Department of the University Hospital of Brazzaville \\ ${ }^{7}$ Anatomopathologist, Professor at the Faculty of Medicine, Head of Service, Pathological Anatomy Laboratory \\ of the University Hospital of Brazzaville
}

Corresponding Author: Fidele Mambouene

\begin{abstract}
Introduction: Gastric adenocarcinoma is the most common gastric malignancy (over $90 \%$ of gastric cancers) and remains a global public health problem.

The aim of the study was to determine the epidemiological and histopathological aspects of gastric adenocarcinoma in Brazzaville.

Material and Methods: The epidemiological and histopathological profile is determined through a descriptive study, collecting retrospective data spread over a period of 11 years (January 2008December 2018), based on consultation of the departmental histology registers, pathological anatomy and cytology. For each case, age, sex, location, pTNM stage, location and histological type were collected.

Results: 93 histologically confirmed gastric adenocarcinomas were collected during the 11-year period. The mean age of the patients was 54.5 years. The sex ratio was 2 in favor of men. The antral and fundal localization were more frequent ( $74.2 \%$ and $20.4 \%$ respectively). Of the 2 operative parts collected, one was T2N1 and the other T1N0. Tubular adenocarcinoma was the most common histologic type $(51.6 \%)$, followed by independent cell adenocarcinoma (34.4\%), papillary adenocarcinoma (11.8\%), and mucinous adenocarcinoma $(2,2 \%)$
\end{abstract}

Conclusion: gastric tubular adenocarcinoma was the most common histological type in Brazzaville.

Keywords: epidemiology, gastric adenocarcinoma, histological type

\section{INTRODUCTION}

Gastric adenocarcinoma develops from the gastric epithelium. Its incidence has been declining for 50 years in Western countries. However, although their annual incidence has declined significantly, it remains one of the top ten global causes of cancer-related mortality and constitutes a global public health problem [1]. Africa is a low risk region for gastric cancer, Western Europe and North America are medium risk regions, and the highest incidence is reported in Japan, followed by China, America. Southern and Eastern and 
Southern Europe [2]. The incidence of gastric cancer has been declining for 50 years in Western countries, $1,033,701$ cases of gastric cancer were diagnosed in 2018 [3]. However, although their annual incidence has declined markedly, currently gastric cancer is the third leading cause of cancer death worldwide, with two-thirds of deaths still occurring in low-income countries and 782,685 (8.2\%) cases of cancer. deaths occurred in 2018 [4]. The recognition of the carcinogenic role of Helicobacter pylori infection is the main advance of the last decade, added to this a diet rich in salt and nitrates and then poor cold storage of food. Prevention of infestation by this germ may be able to decrease the incidence of this cancer. Most gastric cancers are diagnosed in patients at an advanced stage [5]. In our country, in 1993 IBARA et al during a study on upper digestive pathology in Congo concerning 2393 endoscopy performed at CHU-B found 22 cases of gastric cancer, ie a percentage of $3.6 \%$ [7], in 2004 PEKO et al during a study on the histo-epidemiological profile of digestive cancers found gastric cancer in third place digestive cancers [8]. In order to complete the missing data, the aim of this study was to collect all the cases of gastric adenocarcinoma confirmed histologically over a period of 11 years at the Laboratory of Anatomy Pathology (LAP) of Brazzaville Hospital and University Center (CHU-B) and to describe the epidemiological and histological aspects in order to contribute to the improvement of its care.

\section{MATERIAL AND METHODS}

This is a descriptive study, collecting retrospective data from the histology registers of the LAP of CHU-B. Patients who underwent a histological analysis and whose diagnosis of gastric adenocarcinoma confirmed in the LAP histology registers of CHU-B from January 2008 to December 2018 were included. All non-epithelial gastric cancers were excluded from the archives. The following variables were collected: frequency, age, sex, location, histopathological type of these tumors. Data analysis was done by Epi info software. We then compared these different data with those in the literature.

\section{RESULTS}

Over the 11-year period, we identified 93 cases of gastric adenocarcinoma collected at the LAP of CHU-B and confirmed histologically. These were 31 women $(33.33 \%)$ and 62 men $(66.67 \%)$. The sex ratio was 2 in favor of men. The average age was 54.5 with extremes of 23 and 86. Distribution of the number of cases by age group is described in the table The antral and fundal localization were frequent (69 cases and 19 cases respectively. The 2 surgical specimens identified gave 1 case $\mathrm{T} 2 \mathrm{~N} 1$ and 1 case T1N0

Table 1: Distribution of number of cases by age group

\begin{tabular}{|l|l|}
\hline Age group & Number of cancer case \\
\hline$[10-20]$ & 0 \\
\hline$[21-30]$ & 5 \\
\hline$[31-40]$ & 3 \\
\hline$[41-50]$ & 17 \\
\hline$[51-60]$ & 33 \\
\hline$[61-70]$ & 28 \\
\hline$[71-80]$ & 5 \\
\hline$[81-90]$ & 2 \\
\hline
\end{tabular}

Table 2: Distribution of number of cases according to histological type

\begin{tabular}{|l|l|}
\hline Types Histological & Number \\
\hline Adénocarcinoma Tubular & $48(51,6 \%)$ \\
\hline Adénocarcinoma Papillaire & $11(11,8 \%)$ \\
\hline Adénocarcinoma Mucineux & $2(2,2 \%)$ \\
\hline Adénocarcinoma with independent cells & $32(34,4 \%)$ \\
\hline Total & 93 \\
\hline
\end{tabular}

\section{DISCUSSION}

Our objective was to describe the epidemiological and histopathological aspects of gastric adenocarcinoma in Congo Brazzaville. The data were collected in the histology registers of the LAP of the CHUB. These results are valuable for health decision-makers in order to improve the treatment of gastric cancers occupying third place in digestive cancers in Congo Brazzaville, after colorectal and hepatic cancer according to the Brazzaville cancer registry from 2017-2018. Thus, the epidemiological and histological profile of gastric cancers at CHU-B seems be identical 
to that described in Africa. Indeed, according to several African authors and as in our study, gastric cancer is predominant in men and the average age is between 50 and 60 years [6-11]. In Morocco, it ranks first among all digestive cancers [12]. In Rwanda, gastric cancer constitutes $9.9 \%$ of cancers in men and $6.6 \%$ in women [13]. In Kivu (Democratic Republic of the Congo), it is estimated at $11.7 \%$ for men and $12.2 \%$ for women [10]. In Cotonou, gastric cancer was found in patients with an average age of 56 years, the man was more affected than the woman with a sex ratio of 1.4 [6.9].

In Madagascar, it has been estimated at $25 \%$ of digestive cancers and mainly affects humans [14]. Overall, gastric cancer is about twice as common in men as in women worldwide [13]. The antral localization was the most frequent with 54\%. In Rabat (kingdom of Morocco) Khali Abdellah Ben et al found a predominance of the antral location with $52 \%$ [21]. In addition, the annual frequency of gastric cancer varies among authors and among study populations. In our series, it was 8.9 cases per year. Bagnan et al found 4.6 cases per year in Cotonou while Peghini et al reported 14.4 cases per year in Madagascar [6.14]. These variations are explained in part by the diversity of the study populations. Bray et al in their study found a total of 1,033,701 new cancer cases and 782,685 death cases occurred in 2018 and $70 \%$ of these cases occurred in developing countries [15]. The work of PEKO et al had shown that in Congo gastric cancers rank third among digestive cancers [8]. However, gastric cancers do not seem to be well documented in many African countries. The main limitations are the lack of diagnostic facilities and the lack of cancer registries in some countries. In addition, most of the work relates only to populations hospitalized in large city structures.

They are more often mono-centric and do not allow the results to be extrapolated to the general population. The lack of an adequate technical platform is another difficulty in getting to know the data on gastric cancer in Africa. Indeed, the symptoms are nonspecific and the centers performing endoscopy are not numerous and are most often under-equipped. In the context of Congo Brazzaville, specialists to examine patients are in short supply and unevenly distributed. Gastroenterologists (currently around 20 for 5 million inhabitants) have always practiced in the two large cities, Brazzaville and Pointe Noire.

The pathological results showed that adenocarcinoma was the most common histological type found. This finding is identical to that of other African and European authors [10]. In developed countries, it is thanks to advances in early diagnosis and management that the prognosis has improved. In addition, the decrease in the incidence of gastric cancer is believed to be due to improved diet, good cold storage of food and a decrease in Helicobacter Pylori infection in these countries [16-20].

\section{CONCLUSION}

Better management of gastric adenocarcinoma can only be conceived through epidemiological studies allowing a better understanding of environmental or infectious risk factors and the identification of subjects at risk. Gastric tubular adenocarcinoma is the most common histologic type. In general, regardless of the histological type, the prognosis of gastric adenocarcinoma remains unfortunate in our region, affecting a young population, thus minimizing the chances of any curative treatment. Better management of gastric adenocarcinoma can only be conceived through epidemiological studies allowing better knowledge of environmental or infectious risk factors and the identification of subjects at risk.

\section{ACKNOWLEDGEMENT}

Sincere thanks to all the dear masters who participated directly or indirectly in the development of this work 
Fidele Mambouene et.al. Epidemiological and histopathological profile of gastric adenocarcinoma at Brazzaville University Hospital.

Conflict of Interest: The authors declare no conflict of interest

\section{Source of Funding: None}

\section{REFERENCES}

1. Bouvier AM, Remontet L,Jougla E, et al. Incidence of gastrointestinal cancer in France.Gastroenterol clin Biol $2004 ; 28: 877-8$

2. Mellouki I, Laazar N, Benyachou B, Aqodad N, Ibrahimi A. Epidemiology of gastric cancer: experience of a Moroccan hospital. Pan Afr Med J. 2014 Jan 22;17:42.

3. F. Bray, J. Ferlay, I. Soerjomataram, RL Siegel, LA Torre and A. Jemal, "Global Cancer Statistics 2018: GLOBOCAN Estimates of Global Incidence and Mortality for 36 Cancers in 185 Countries", CA : a Cancer Journal for Clinicians, vol. 68, no. 6, pp. 394-424, 2018.

4. Klingelhöfer D, Braun M, Schöffe N, Brüggmann D, Groneberg DA. Gastric cancer: bibliometric analysis of epidemiological, geographical and socioeconomic parameters of the global research landscape. Int $J$ Health Policy Manag. 2020;x(x):x-X..

5. Aparicio T, Yacoub M, Karila-Kohen $\mathrm{P}$, René E. Gastric adenocarcinoma: fundamental concepts, diagnosis and treatment. EMC. 2004; 1 (1): 1-84.

6. Bagnan K.O, Padonou N, Kodjoh N, et al. Stomach cancer about 51 cases observed at the Cotonou CNHU. Black African Medicine 1994; 41 (1): 39-43

7. JR Ibara, B Moukassa, A ITOUANGAPORO. Upper digestive pathology in Congo concerning 2393 endoscopies performed at the Brazzaville University Hospital. Medicine of Africa; 1993.40 (2)

8. J.F. Peko, J.R. Ibara, J.M. Dangou, C. Gombe Mbalawa. Histo-epidemiological profile of 375 primary digestive cancers at Brazzaville hospital. Med Trop 2004; 64: 168-170

9. Zinsou C P, Foum L, Zohoum T. Epidemiological aspects of cancers at the national hospital and university center of Cotonou. Med Afr Noire 1990; 37 (5): 2306

10. Bourdeaux L, Renard F, Ginace PL, et al. Incidence of cancer in katana hospital, East
Zaire, 1983-1986. Ann Soc Belg Med Trop 1988; 68: 141-156

11. Raharisolo Vololonantenaina C, Pecarrere JL, Roux JE. Cancer in Madagascar. Experience of the Pasteur Institute of Madagascar from the beginning of September 1992 to the end of June 1996: The bio-epidemiological specificities of the ocean.Bull Soc Pathol Exot1998; 91 (1): 17 21

12. M. Fadlouallah, H. Krami, I. Errabih, N. Benzzoubeir, et al, Gastric cancer: epidemiological aspects in Morocco, Journal Africain du Cancer, February 2015, Volume 7, pp 8-15 |

13. Ngendahayo P, Parkin DM. Cancer in Rwanda. Relative frequency study Bull cancer 1986; 73 (2): 155-6

14. Peghini M, Rajaonarison P, Pecarrere JL, et al. Epidemiology of cancers of the digestive tract in Madagascar. Contribution of 14,000 endoscopies performed at the soavinanandriana hospital center in Antananarivo, Med Afr Noire 1997; 44 (10): 518-21

15. Jemal A, Bray F, Melissa M, et al. Global cancer statistics. Ca Cancer J Clin 2011; 61 (2): 69-90

16. Bertuccio P, Chatenoud L, Levi F, et al.Recent patientsin gastric cancer.A global overview.Int J Cancer 2009 ;125(3) : 666-7

17. Parkin DM. The global health burden of infection-associated cancer in the year 2002.Int J Cancer2006;118(12):3030-44

18. Kawakami E, Machado R S, Ogata SK,et al.Decrease in prevalence of helicobacter pylori infection during a 10 years periode in Brazilian children.Arq Gastroenterol2008;45(2) :147-51

19. Tkachenko MA, Zhannat NZ,Emman LV,et al.Dramatic changes in the prevalance of Helicobacter pylori infection during childhood a 10 years follow-up study in Russia.J Pediatric Gastroenterol Nutr. 2007; 43(4) $428-32$

20. Chen J,Bu XL,Wang QY, et al.Decreasing seroprevalence of helicobacter pylori infectionduring 1993-2003 in Guangzhou,southem china.Helicobacter $2007 ; 12(2): 164-9$

21. Tkachenko MA, Zhannat NZ,Emman LV,et al.Dramatic changes in the prevalance of Helicobacter pylori infection during childhood a 10 years follow-up study in 
Fidele Mambouene et.al. Epidemiological and histopathological profile of gastric adenocarcinoma at Brazzaville University Hospital.

Russia.J Pediatric Gastroenterol Nutr. 2007; 43(4)428-32

22. Chen J, Bu XL, Wang QY, et al. Decreasing seroprevalence of helicobacter pylori infection during 1993-2003 in Guangzhou, Southern China. Helicobacter 2007; 12 (2): 164-9

23. Khali, Abdellah Ben; Belamaalem, Souad; Khadmaoui, Abderazzak; Qyou, Ali; Ouazzani, Houria Chahed; et al. Epidemiological profile of gastric adenocarcinoma: retrospective study.
International Journal of Innovation and Applied Studies; Rabat Vol. 16, No 3, (Jun 2016): 482-487.

How to cite this article: Mambouene F, Boumba A, Mouamba $F$ et.al. Epidemiological and histopathological profile of gastric adenocarcinoma at Brazzaville University Hospital. Int J Health Sci Res. 2021; 11(9):192196. DOI: https://doi.org/10.52403/ijhsr. 20210930 